\title{
RETURN MIGRATION:
}

\section{DILEMMA OF IMMIGRANTS FROM DEVELOPING COUNTRIES}

MUSA SHALLAL

Associate Professor

Department of Sociology

College of Humanities and Social Sciences

Maqam Females Campus - Building C1

United Arab Emirates, Al Ain

Email:mshallal@gmail.com/Shallal.m@UAEU.ac.ae

\section{ABSTRACT}

PURPOSE: This paper demonstrates how immigrant families from developing countries deal with the return home dilemma. It does this by applying Dumont and Spielvogel (2008) model to the situations of some selected Sudanese migrant families in different countries.

DESIGN/METHODOLOGY/APPROACH: A group of immigrant Sudanese families had been interviewed using different methods during the years 2011, 2012, and 2013 in the GCC, Sudan, and a third group in North America. The interviews were usually with the fathers of the families. All of them are married and have children. Henceforth, these families were compared with each other, as well as with other countries, to examine the dilemma of returning home, which faced this segment of Sudanese migrants in the countries of destination, as an example of immigrants from developing countries.

FINDINGS: In general, the results of the study indicate families in the Gulf States share one common pattern. All cases (with temporary residence) seemed to have returned to their country of birth (Sudan); this is in contrast to the North American families (with permanent residence). In addition, the North American families appeared to have migrated to more than one destination country. Almost all the families in North America divided their time between Sudan, USA and Canada; they 
indicated a final return to Sudan would be likely. Finally, all the families of the two groups were shown to be satisfied with their decision to migrate out of Sudan.

ORIGINALITY/VALUE: This paper adds new empirical knowledge to the issue of immigrants' return from the developing countries. Its findings are therefore important for a number of countries.

\section{KEYWORDS: Home return, return migration, Sudanese immigrants, Sudan, UAE, USA.}

REFERENCE to this paper should be made as follows: Shallal, M. (2017) 'Return migration: dilemma of immigrants from developing countries', Int. J. of Sudan Research, Vol. 7, No. 2, pp. 67-84.

\section{INTRODUCTION}

The issue of return to the homeland is one of the greatest concerns facing migrants worldwide (Carrión-Flores, 2007), with particular emphasis on the first generation of migrants from developing countries. For them the idea of return represented a matter of endless concern in their minds, and this continuous feeling gave them more strength and patience, which helped them to bear the difficulties of expatriation and all its consequences. Because the majority of developing countries' migrants have left their homes for reasons against their will, usually due to expulsion, the issue of going back always remains attractive and from time to time they fantasize about it, even if the period of their migration is prolonged. Some of the migrants described their situation as being in exile. Others introduced new names and concepts that were attributed to the issue of returning to the homeland, such as "return elusion" (OECD, 2006); others considerer it as a new type of migration to which migrants are exposed to around the world.

Studies confirm that the issue of returning home became controversial, and that this desire of going home increased with regard to:

(1) the cases of temporary migrants;

(2) the economic situations of the immigrants;

(3) the country of origin;

(4) the country of migration (Dustmann and Kirchkamp, 2002; Yang, 2004; Shah, 2001; Kuşçu, 2014; Thieme, 2012; Tannenbaum, 2007).

However, the answer to the question of why people return may have something to do with the question, why do people migrate in the first place. This disputable issue has become a source of many social and economic concerns of international migrants in many developing countries, such as Kazakhstan, Turkey, Portugal, Egypt and many other African and Asian countries, where, in some of them, a high percentage of families are directly dependent on remittances. 
Research on returning migrants to their homeland has focused more at the microeconomic level rather than on the socio-cultural and political impacts. However, for some studies the economic depression of 2008 has accelerated research into the states receiving immigrants, paying more attention to this issue (Kalia, 2015). This includes the European Parliament, Spain, United States, Malaysia, Australia, and Mexico (Rietig and Villegas, 2015). Some current related literature has dealt with this in an attempt to discover the real reasons that drive migrants to return to their home countries. This may be encouraged by some major factors. The following sections discuss this in more detail.

\section{THE ECONOMIC FACTOR}

Migrants are motivated by economic factors; it is confirmed by a number of studies that the migrants' economic situations are strong determinant factors on the question of returning home. This is because the return is coupled with the period that migrants spend in the country of destination; it is also joined with the work they do in that country. Each of these has their economic significance, for the migrants and the countries hosting them. They also have direct effects on the issue of determining when to go back. Cobb-Clark and Stillman (2103) and Yahirun (2014) found that the most influential factors behind taking the decision to return home are (1) the age of the migrant person, and (2) the country from which they came. The findings of their studies indicated that more than half the Turkish migrants who returned home from Germany became economically active; most of them owned businesses that yielded good material benefits.

Others indicated that the decision to return home depended basically on what benefits the migrants had achieved. For example, migrants from Kyrgyzstan in Russia, stated that their return home depended on achieving a certain level of economic status and having collected a certain amount of money, but not before reaching their retirement age. Studies of the International Organization for Migration (IOM) believe that the return of migrants to their home countries has a direct relation to the economic development there, and that migration and development are highly interdependent processes in the sense that return migrants bring home not only money but also human capital and technical knowhow to their homes. Some of the African studies confirmed this, and that the reasons for African migrants' return home, such as Ghana, and Cote d'Ivoire, Senegal and other west and northern African countries, is that they are inspired by their desire to invest their savings there and to take part in development of their countries. They bring with them, in addition to their savings, high professional expertise and advanced technology usage skills, together with the introduction and spreading of new fields of knowledge promoting changes in family life and in the workplace. 


\section{THE SOCIAL FACTOR}

One of the major causes that drives migrants to return home is the social one, i.e. some of the elderly migrants who reached retirement age, who have succeeded or failed in fulfilling many of their objectives from migration, and who thought that there was no reason for their migration to continue, returned home as their feelings towards their homelands were still very strong. In addition, elderly migrants would like to return to spend the rest of their days at home, among their extended families, and those who still lived from their childhood and youth time friends. Some believe that the decision to return depends basically on two elements, i.e. the preparedness and the will of the migrant persons, in addition to their personal ability in collecting material and non-material resources that would secure them a good life when they return home. Other studies added that the migrants' decision to return home is much influenced by the family, i.e., a family decision. It is noted in some studies (Glennie and Chappell, 2010) that some migrants are driven by their families' needs to look after their elderly at home, such as fathers and mothers and the rest of the extended family members.

This is not confined to migrants from African countries only; it is also shared by migrants from Jamaica to the USA. The studies that tackled the situation of this group highlighted the factors of investment and participating in development of the homelands, in addition to the families' impact (Thomas-Hope, 1999).

\section{THE CULTURE FACTOR}

For some other migrants, culture is the major factor behind their decision to return to their home countries: this is when migrants fail to adapt to the host communities. This point was raised by Efstratios et al. (2014) and others about the Albanians who migrated to Athens. Their findings indicated that these immigrants were faced with the difficulties of integrating into Greek society, racism and unemployment (Efstratios et al., 2014).

The migrants' social networks also play a major role in the issue of their return; as long as such networks became stronger and are able to provide services to their members, they help more in lessening the migrants' opportunities to go home. It is also believed that migrants who worked in and then returned from the communities of those advanced industrial countries, developed new cultures different from those of their original countries. Some studies noted that fertility rates of Egyptian migrants who return to Egypt from the Arabian Gulf area have increased to those similar to the prevailing conditions in that wealthy area. Egypt used to impose a very strong policy of birth control over the previous two decades (El Sheikh, and Al Zohairy, 2013). Returnees from the Arab rich oil countries acquire the ability to engage in private business. The issue of the global migration is becoming increasingly diverse, not only in its nature but also in the structure of the flow of labour migration and the migrants destination; it is not easy therefore to define 
all factors that drive migrants to return home. However, in addition to the above mentioned factors, causes such as an improved political and economic situation at home, the sense of belonging towards their homeland and its culture, plus success in achieving the goals of the immigration are identified as important causes in pulling migrants back to their homeland (Glennie and Chappell, 2010).

However, the issue of returning home may not be attractive to all migrants. Some of them face some sort of dilemma that is difficult for them to solve, and therefore makes their decision to return home very difficult as well. The dilemma is when they have to choose between returning to their home countries despite the poor economic and social conditions, or to begin searching for another host country. This difficult situation is faced by a large number of migrants who migrated to the rich countries of the Cooperation Council for the Arab States of the Gulf (GCC) (see Table 1), namely Bahrain, Kuwait, Oman, Qatar, Saudi Arabia (KSA), and United Arab Emirates (UAE), where the percentage of expatriates is about $87 \%$ of the total population in Qatar, and about 84\% in the UAE (Emirates247 News, 2013). International migrants in this region (GCC) are described as "temporary migration", or as "guests". This is attributed to the system of open work permits that are given to those migrants named "Kafala" (Malit Jr. and Al Youha, 2013). This system obliges them to leave the host country as soon as this open contract expires; he or his family members are not allowed to stay unless they find another job that grants them residence visas, and this is called the sponsorship system. A migrant can also remain if he has one or more of his sons or daughters working in the area under a legal contract and earning an income that can sustain the family if they stayed. In this case they are allowed to sponsor their parents.

Table 1: Percentages of Expatriates in the GCC

\begin{tabular}{|l|l|l|l|l|l|l|}
\hline States & Bahrain & Kuwait & Oman & Qatar & $\begin{array}{l}\text { Saudi } \\
\text { Arabia }\end{array}$ & UAE \\
\hline $\begin{array}{l}\text { Percentage } \\
\text { expatriates }\end{array}$ & $\begin{array}{l}55 \% \\
(\mathrm{UN},\end{array}$ & $\begin{array}{l}70 \% \\
\text { (PACl, }\end{array}$ & $\begin{array}{l}30 \% \\
(\mathrm{UN},\end{array}$ & $\begin{array}{l}85 \% \\
(2014,\end{array}$ & $\begin{array}{l}30 \% \\
\text { (UN, }\end{array}$ & $\begin{array}{l}80-90 \% \\
\text { (UN 2013 } \\
\text { estimate) }\end{array}$ \\
\hline
\end{tabular}

Therefore large numbers of migrants face the dilemma of staying/returning home after the expiry of their contracts, with a special reference to those coming from developing countries with weak economies, such as some Arab, African and Asian countries. This is because the reasons that have pushed them out are still prevalent there, and form expelling factors to them. At the same time they face the immigration laws and employment regulations in force in the host countries, which also represent push factors for them, particularly in the GCC. 
However, the situation is different when we speak about migrants to Europe, the USA, and other industrial countries, where many migrants enjoy different residence statuses that may allow unlimited or permanent residence. In these countries, the issue of their return to the mother countries is not a matter of concern that bothers them as compared to the migrant groups in GCC. Among this latest group in this area are the migrants from Sudan (see Table 2).

Table: 2. Sudanese Migration by Receiving Country, 2010

\begin{tabular}{|l|l|l|}
\hline Receiving Country & Number of migrants & Percent \\
\hline Saudi Arabia & 279,409 & 28.9 \\
\hline Uganda & 191,103 & 19.7 \\
\hline Yemen & 126,109 & 13.0 \\
\hline Kenya & 73,076 & 7.5 \\
\hline United States & 39,573 & 4.1 \\
\hline Chad & 38,769 & 4.0 \\
\hline United Arab Emirates & 30,200 & 3.1 \\
\hline Australia & 24,281 & 2.5 \\
\hline Jordan & 20,766 & 2.1 \\
\hline Canada & 14,656 & 1.5 \\
\hline United Kingdom & 14,134 & 1.5 \\
\hline Oman & 12,626 & 1.3 \\
\hline Ethiopia & 9,157 & 0.9 \\
\hline Other Countries & 94,282 & 9.7 \\
\hline Total & 620,405 & 100.0 \\
\hline
\end{tabular}

Source: Thomas, Stuart (2012). Sudan Migration Profile.

This paper will tackle how the Sudanese communities abroad dealt with the issue of returning to their country, based on case studies of some selected families in different countries, namely the USA, Sudan, and the UAE. Then the paper will apply the Dumont and Spielvogel (2008) model to the situations of these Sudanese migrants' families. 


\section{METHODOLOGY}

\section{PARTICIPANTS}

Some migrant Sudanese families had been interviewed using different methods during the years 2011, 2012, and 2013. The interviews were diversified: some of them through direct interviews applying an in-depth interview approach, some of them by telephone and others by correspondence. A group of families had been interviewed in the Gulf area, a second group in Sudan, and the third group in the USA in the mid-west states. The interviews were usually with the fathers of the families. At the beginning, all participants migrated abroad looking for better opportunities for themselves and for their family members; they have been living abroad for ten years or more. All of them are married and have children. Henceforth, these families had been compared to each other to examine the dilemma of returning home that faced this segment of Sudanese migrants in the countries of destination. These case studies of the Sudanese immigrant families at the GCC are presented in the next sections.

\section{CASE STUDIES OF SELECTED IMMIGRANT FAMILIES}

\section{CASE STUDY 1: Mrs Asmaa}

The first case is the family of Mrs Asmaa, who is a Sudanese widowed mother, who lived in Abu Dhabi. She said during an interview, that her late husband died some years ago after serving about 30 years in the UAE, leaving her with two sons and a daughter. One of the two sons is now on a scholarship studying medicine in Russia; the other is a student at Abu Dhabi University, intermediate year, while the daughter is still at secondary school level. This lady is a salaried teacher with a very limited income. She received limited financial help from one friend of her late husband. She complained about the burden of university and school fees, and is seeking a scholarship for her son who studies at the University of Abu Dhabi; if she fails, she will be compelled to stop his university study.

She was asked why she did not return to Sudan, where the situation may be better. She replied that, based on her journey to Sudan she expected quite the reverse; she did not own a house there, and there was only her father's house where there is not enough room for her family in addition to her brothers and sisters, i.e. she would put further burden on them. She said that the standard of living in UAE is far better, in terms of education and health services, and the pay level is also better. Sudanese and other migrants from Middle Eastern countries have no problems with adapting to life in the UAE, due to the existence of many common factors between them and the UAE's people, e.g., language, religion and many other Arabic traditions, as mentioned earlier.

Because of such factors, Asmaa does not think of going back to Sudan since she is still able to continue living in the UAE. She hopes that her two sons would graduate 
one day and find good jobs in the UAE, and therefore enable her to extend her stay in the UAE. At the moment she has no plans to return home; maybe in the future, she added.

\section{CASE STUDY 2: Abu Faisal}

The second case is the Abu Faisal family. Abu Faisal represents a different case: some Sudanese families returned and settled in Sudan for some years, but came back to the UAE. He came to the UAE with his family during the 1970 s to work in one of the Government departments; then he resigned from his post, received his service gratuity and went back to Sudan in 2000 . There he invested his money in the procurement of a Chinese-made wheat flour mill in the Gezira region, central Sudan, where wheat and other cash crops are grown. The flour mill succeeded commercially, and he led a settled life with his family, his wife and their five children.

However, after some years the flour mill stopped working due to low productivity of wheat in the region. Many farmers were displaced due to high taxes that were levied on them by more than one of the government departments, causing the cost of production to increase, and returns to decrease, resulting in failure to cover all agricultural expenses. With the displacement of the wheat farmers, the factory stopped, and Abu Faisal's attempts to find alternatives for locally produced wheat failed. He sought to import Australian wheat, but was struck by the fact that import was monopolized by a single national company that controlled wheat prices at a level with which he could not cope. He failed to obtain any finance from any financial institution in Sudan. Then he turned to investment in a services project, i.e. establishing a travel agency, which also failed due to the local taxation policy. Then he entered into a partnership with his brother, who is a pharmacist, to establish a pharmacy. But the project stopped despite its success, due to the difficult regulations imposed on pharmacies by the authorities concerned, e.g., one must be a pharmacist himself in order to enter into a partnership to establish a pharmacy, and so he left the project to his brother.

At that point, Abu Faisal decided that Sudan was not a suitable place for him to undertake investment and settle with his family. He left home after 10 years of unsuccessful attempts and came back to the UAE in 2010 so as to invest the remainder of his money there. However, the consequence this time was family breakdown: three sons and one daughter remained in Sudan to continue their university education, the second daughter joined Sharjah University, UAE, his wife lived in Fujairah after completing her studies in medicine and is now practicing at one of Fujairah's hospitals. Abu Faisal is now resident at Al Ain city in a different emirate (Abu Dhabi), and splits his time between the two emirates in order to follow up his new business at Al Ain.

Some studies indicated that family breakdowns and dispersal of their members in more than one place causes psychological pains and stress, particularly with regard to those family members left back at home. Such studies indicated that women 
are more vulnerable to depression and other psychological illnesses (Shallal and Abdelrahman, 2009; Bhugra and Jones, 2001).

\section{CASE STUDY 3: Abu Mohamed}

The third case is that of Abu Mohamed, who is considered to be representative of the vast majority of Sudanese families who returned and settled at home after a long period of expatriation in the Gulf States: he is considered to be a successful example. He migrated to the UAE in 1977 where he served in one of the government institutions at Al Ain city in Abu Dhabi. He used to be an employee of excellent performance, who received several prizes and certificates of appreciation during his service period; this lasted until 2004, when he resigned from his job and returned to Sudan. When asked about the reasons for his resignation after a service period of 27 years (!!), he mentioned that he missed home and wanted to spend the rest of his life among his kinsmen.

Abu Mohamed had lost his first wife some years after his migration to the UAE, and then he married to his wife's sister, in accordance with the customary practice in Sudan, i.e., when a husband loses his wife and remains with motherless children. Usually the wife's family advises him to marry her sister, if she had one, otherwise, he could marry one of her relatives. The purpose of this practice is to secure appropriate care for the children, assuming that those relatives (wife's sister or relative) has a very close relationship and acquaintance with the children and their widowed father. Abu Mohamed succeeded during his expatriation period in UAE in providing financial assistance to his six brothers until they were able to graduate from university. He was also able to construct a house for his parents, contribute financially to the wedding of his brothers and the construction of their houses.

When he returned to Sudan, he made use of his service gratuity, for more than 25 years of service, to resume his old profession in the storage business, which he did in the UAE. He established a store to sell vehicles' spare parts. He also entered into partnership with one of his relatives in the transport business between different parts of the Sudan, but the business failed due to the death of the partner. After this he moved to work as a contractor, and he is still doing that successfully. He has a decent standard of living together with his second wife, who gave birth to six more children, in addition to his two children from his deceased wife, i.e., eight children, five males and three females. His eldest son graduated as an architect from a Sudanese university and is employed by a company there. The second one recently graduated from the faculty of mechanical engineering, and the rest of them are still continuing their education at the different levels.

When asked whether he wished to return to the UAE for work, Abu Mohamed answered decisively that he did not. He was interviewed at Al Ain city while he was preparing to leave for Sudan after his brief visit, during which he intended to call on his old friends with whom he spent the blossom of his youth, and to do some work relating to his business in Sudan. 
Asking about the factors that helped him to overcome the "culture shock", which usually faced many of the Sudanese families upon their return to the Sudan, he answered that he formed a group of about 130 people who ended their service contracts and returned home. These were from his acquaintances that used to live in Al Ain city during their residence in the UAE. Members of that group met at definite periods, and were keen to share and take part in all their family occasions. The group members were now in the process of joining the membership of a larger voluntary organization, under the name of the Sudanese-Emirati Friendship Society, which has been recognized by the Sudan government and allotted a plot of land with a total area of 2,000 sq. metres for the construction of the society's headquarters in one of the most luxurious areas of Khartoum. Abu Mohamed mentioned that the group will have a significant effect in reducing the impact of the big transition from the quality of life in UAE to that in Sudan. There were many factors which brought together members of this group, who are characterized by homogeneity of ideas and ways of thinking and acceptance of each other, despite the differences of their professions. He indicated that he suffered serious difficulties in adapting to life in Sudan at the beginning of his return. He tried to reach his old friends, but that was not easy because some of them died, and others have changed a lot. This also led to changes in the way he and his friends dealt with each other, due to a lack of the common bonds that were weakened by the long periods of his absence in the UAE.

\section{CASE STUDY 4: Abu Dalia}

Abu Dalia's represents a different story of successful expatriation. A meeting was held in his house at "Althawra" residential quarter one summer night. Abu Dalia had completed his education at an old high-standard government school, established during the British colonial rule in Sudan. After graduation he worked as an accountant in a government department. He is in his early 70 s, a married man with three daughters and one son, all of them in their 20 s.

He started by mentioning how he was selected for work in KSA at the beginning of the 1970s: it was fashionable at that time to migrate. Migration to KSA and other Gulf states was attractive for many qualified employees. He received an attractive offer that could not be refused, although he was not one who believed in living outside Sudan. However, political and economic pressures made him change his mind and opt for expatriation. He travelled to the city of Riyadh to work as accountant in a big governmental department. A few years later he decided to get married and brought his wife from Sudan, bought a new Japanese car, and lived in one of Riyadh's good residential neighbourhoods.

Life went on and Abu Dalia had his five children there and succeeded in buying a plot of land in Omdurman city. Years passed before he was able to start building his house. After more than 20 years, the Saudi department where he worked decided to change the service contracts of all its expatriate employees. They were forced to choose between continuing their service contracts and receive only half their 
current pay, or be dismissed from service and given their service gratuity. Many expatriates preferred the second option; among them was Abu Dalia, who had to resign and return to Sudan or look for another job.

The problem he faced was that his house in Sudan had not yet been completed. He decided to send his family to Sudan after he failed to find a job to sustain his family in KSA. He stayed in KSA to search for a job, but he exhausted all the open opportunities for him to find one through his Saudi acquaintances, who had known him for 30 years. After two years he was certain that there was no probability of any job, moreover his separation from his family became unbearable, so he returned home to face a state of affairs that he had not been accustomed to for at least three decades. Although he left KSA he had not cancelled his residence hoping that another chance for work there might come. Days passed, and his family struggled to educate the children, his service gratuity was gone in completing the house, children's education, medical services and the cost of living. All the family had undergone a very tough experience, facing the fact that there was no way to return to KSA, they had to adapt to living in Sudan, however hard that was. His wife's strong character and her unshaken belief to settle in Sudan without thinking of KSA again, helped him to overcome that hardship.

Another factor that helped to alleviate their hardship was that Abu Dalia imported his Japanese car, and owned a relatively big house, although not completely finished. Fifteen years after their return to Sudan, his eldest son graduated from university and was employed in a financial firm; the eldest daughter also graduated and occupied many temporary jobs that sometimes required her to work overnight; while the second daughter also graduated but could not find a job. The third daughter could not carry on with her university education in a regular manner, due to economic difficulties suffered by her family.

Abu Dalia then continued to mention that his elder son is now a refugee in one of the European countries. He was unable to put up with life in Sudan; his work in the above mentioned firm was insufficient to cover his own needs, he was not able to help his family, being the eldest son and he felt more frustrated. He failed to finish the construction of the house despite his irregular attempts to do so. What added to his feelings of bitterness was that he was deprived of his university degree because he was not able to pay his debts to the university. He was forced to take jobs that did not require a university degree. As he could not find a better job inside or outside Sudan to satisfy his personal and family needs, he resorted to political asylum and settled in a European country where he got married to a Sudanese lady. He will obtain nationality of that state in a few years. He sent some money to his mother from time to time.

Abu Dalia said that he is content with his pension pay from the government of Sudan, and some money from his sons and daughters, in addition to his political work. He concluded that he will not forget his experience in KSA, and that if he is given another offer to go there he will go, despite his weak sight. His three 
daughters shared this view, but his wife would not agree to leave Sudan again, and will stay at home for the end of her life, whatever happens.

The following sections discuss cases from the USA and Canada.

\section{CASE STUDY 5: Abu Rabie}

A meeting was held with Abu Rabie in the USA in one of the cities of the northern states, availing his summer vacation with his elder son who worked in one of the large medical corporations in that state. He related the story of his expatriation since the middle of the 1980s, where he joined a special programme sponsored by an NGO with the assistance of the US government. The programme aimed at acquainting all the participants from the "third world" countries with American life and the American community. It allowed the participants to live with American families in different cities inside the USA.

Abu Rabie decided to remain in the USA and not return to Sudan, despite his obligation to the Government of Sudan at the beginning of his scholarship to return. Abu Rabie was able, after completing the period of nine months prescribed for the programme, to bring his family, of two male children, aged two and three, from Sudan. After sustained attempts he succeeded in obtaining acceptance from an American university to join an MSc course in human studies. He was able to work and study at the same time, and managed to cover all the course expenses from the returns of his work. He was helped by one of the American citizens, whom he had known during his work with the NGO, to join the university when he was sure of his dedication to educate himself. Abu Rabie was then able to obtain his MSc within a record time, as his financial ability would not allow any extension of the course period. That same American citizen helped him to continue in his job, and promised to help him to join another university for a PhD programme. After an arduous and long search he was able to obtain acceptance from one prestigious university in one of the northern states, together with securing a job of a Teaching Assistant at the same university. This enabled him to pay the university fees and sustain his family, after having a third baby.

His wife found employment and was able to increase the family's income; the family became a little larger and had more expenses in addition to the university fees. Abu Rabie was able to work additional hours in the farms inside that state in summer, worked as a cleaner and janitor in many of the city's business places where the family had settled down, and so did his wife. After four long years, Abu Rabie obtained his $\mathrm{PhD}$, but failed to find a job appropriate to his degree; likewise his status with regard to immigration regulations did not allow him to work after completion of his study courses.

So he moved with his family to the Kingdom of Saudi Arabia and worked there in a temporary job in one of the universities, but the income was not sufficient to cover all the family's needs. Abu Rabie's pursuit of a better job that suited his qualifications (PhD) never stopped. Eventually, he succeeded (in 1998) in applying 
to one of the UAE's universities, where he was accepted for a permanent job, and he was able to bring his family to the UAE. After 17 years in the UAE, the family obtained permanent residence in the USA. When asked about his return to Sudan, he expressed some hesitation and mentioned that his wife and children refused the idea of returning and preferred to live in the USA, or better in the UAE if that was possible.

\section{CASE STUDY 6: Wad Asheikh}

Wad Asheikh was born in Sudan in 1954, received his university education in Egypt in electrical engineering (communications), and graduated in 1977. He then returned to Sudan where he worked there until 1983. After this, he migrated to the Sultanate of Oman to work as an engineer until 2005, during which time he got married, had two daughters and two sons, and the family obtained the green card that enabled them to have permanent residence in the USA, where they became citizens and moved to live there. Then again, he returned to Sudan, in keeping with the Sudanese government call for Sudanese expatriates' return to work at home. He set up a private company to work in the field of communications engineering. By the beginning of 2009, he had lost all the capital that he invested in the company due to oppressive government policies, corruption at government departments, and harassment owing to his non-membership of the ruling party.

He returned to the USA where his children resumed their university education and some of them got jobs there. His eldest daughter got married in Sudan. His family owned some real estate investments that had been established some time ago. When asked about the idea of returning to Sudan he mentioned that he was planning to do that in the near future to establish his own business in computer maintenance and training. He will work as a book writer also, as he has already started writing a book titled Dictionary of Communications Terminology. His eldest daughter got married to a Sudanese immigrant and settled down in the city where he worked. In 2014 Wad Asheikh was able to finish and publish his book. He and his wife are still in the process of moving between Sudan and America, while plans to settle in either of the two countries are not envisaged yet.

\section{CASE STUDY 7: Abu Alsamha}

Abu Alsamha was born, brought up, and received his education in Sudan. He specialized in Agriculture, and was sent to the USA by his university, to one of the northern states' universities, on a scholarship during the second half of the 1980s to study for an MSc and PhD in Agricultural Engineering. He got married during that time. After he obtained his degrees, he decided not to go back to Sudan, but to stay and work in the USA. To start with he did not succeed in his search for a job to match the field of his specialization, so he worked as translator in one of the medical treatment institutions that was attended by many Arabic speaking people who do not speak English.

However, this job did not stop his search for a suitable job that enabled him to 
practice his specialty in agricultural engineering. At the beginning of 2000 , he was able to find a job in Canada, to which he migrated and got a Canadian passport and citizenship. He became a university teacher in one of Canada's well established universities, where he taught the subject in which he specialized. His wife worked in a private institution. At that time, he already had a son and a daughter, owned a house and settled in Canada. He was able to bring up his children until they became university students. When asked if he intended to return to Sudan, he said he will definitely do so after his children complete their university studies, and after he constructs the family's house on the plot of land he bought in one of the villages of Northern Sudan for that purpose. He seemed content with that decision.

\section{CASE STUDY 8: Abu Ali}

Abu Ali came to the USA on a study mission from one of the Sudanese universities. He joined a university in the mid-west region of the USA from which he graduated at the beginning of the millennium. After his graduation he decided to stay in the USA and not to return to Sudan.

He first worked in the field of medical services in one such institution, as he failed to find a job relevant to his field of specialization. He met a young Sudanese lady in his university to whom he got married. Afterwards he succeeded in obtaining permanent residence in Canada, where he had migrated at the beginning of the millennium. He found a job that was relevant to his specialty in a governmental department, while his wife also found a job in the field of her specialty. Abu Ali and his wife brought two sons and a daughter. The eldest son has already graduated from university, while the second is still at the beginning of his university study, and the youngest in school.

Despite the affluent life Abu Ali and his family had in Canada, he still dreams of returning to Sudan after his children finish their university education. In preparation for this return he bought two houses in Sudan, which he and his family visit every year to have a look at their property. Abu Ali divides his time between Sudan and Canada, and has not yet made a decisive choice where to finally settle.

The following sections demonstrate the model of Various Cases of Return Migration by Dumont and Spielvogel (2008), before applying it to situations of a number of Sudanese immigrant families.

\section{THE APPLICATION OF THE THEORY TO SOME SUDANESE IMMIGRANT FAMILIES}

In general, analysis of returning immigrants found out that some of them returned and stayed at home, others came back to the migrant countries where they first lived, some others have never gone back, or had migrated to a second, third, or a fourth country, where they became the victims of a dilemma. The UN Statistic Division defines returning migrants as "persons returning to their country of 
citizenship after having been international migrants (whether short-term or longterm) in another country and who are intending to stay in their own country for at least a year" (UN Statistics Division, 1998).

According to the model (see Chart 1), immigrants are divided into three patterns: the first pattern (1.1) is when immigrants migrate to a host country (trip one) whether short or long term, and return to their country of citizenship (trip two), making two migrations trips in total. The second pattern (1.2) is when immigrants migrate first to a host country (trip one), then migrate again to second country.

\section{Figure 1: Various cases of return migration}
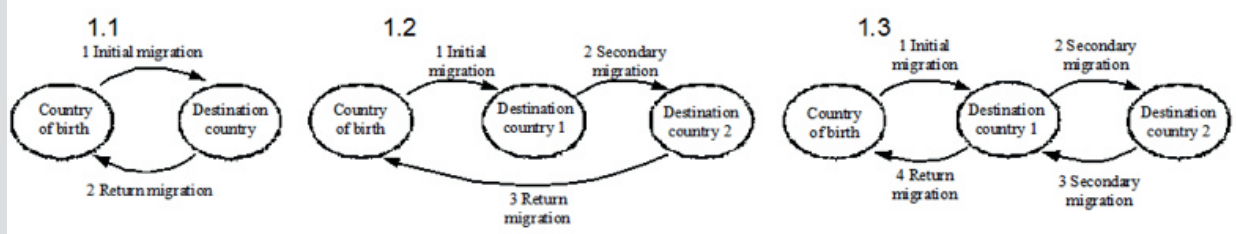

\section{DISCUSSION AND CONCLUSIONS}

Sudanese immigrants are no different from other immigrants around the world concerning their attitude towards home return. Almost all Sudanese immigrants interviewed showed a real desire to return to their homeland one day. Senyurekli and Menjivar (2012) cited a number of studies about different nationalities such as the Filipina, Nicaraguan in the US, the Guatemalan and Salvadoran, Portuguese living in Germany carrying similar attitudes as the Sudanese. What confirms this attitude is the amount of remittances and gifts they send to relatives and friends at home, in addition to the investment they make in their homeland (Senyurekli and Menjivar, 2012). According to Dumont and Spielvogel (2008) when they reach age of retirement, some immigrants from developing countries tend to divide their time between their country of birth and host countries. This observable fact applies to Sudanese immigrants, voluntarily in some countries, particularly in the USA, and compulsorily for those who live in the Gulf region.

To conclude, the immigration patterns of Sudanese families in the Gulf States were compared with the immigrant Sudanese families in North America. In contrast, the immigration pattern of Sudanese families were compared with other families from different parts of the world (Dumont and Spielvogel, 2008). For the sake of 
comparison, eight Sudanese immigrant families from different destination countries were purposively selected, and then Dumont and Spielvogel's (2008) model was applied to the groups. The result of this application is as follows:

\section{FIRST FAMILIES FROM THE GULF}

1. The results indicate the only pattern of the theory that is applicable to the two groups (families from the Gulf and from North America) is pattern 1.1. This pattern is specifically applicable to two cases from the Gulf region; case number three (Abu Mohamed) and case number four (Abu Dalia), where both families made one initial migration journey and one return migration journey respectively;

2. The other two families from the Gulf (Mrs Asmaa, case number 1 and Abu Faisal, case number two) followed a different pattern. Both families made one initial migration journey, a second return, and a third migration journey. Therefore the application is not met on these two families.

\section{SECOND FAMILIES FROM NORTH AMERICA}

3. The findings of the families from North America indicate that the theory is not applicable to them as none of the families made a return migration journey;

4. Case number five (Abu Rabie's family) made three migration journeys to three destination countries, in addition to a fourth migration journey and no return migration (new pattern).

5. Case number six (Wad Asheikh's Family) showed a different pattern from all the other families. This family endured three migration journeys to three destinations before finally resettling in the first destination country, without making a return migration to the country of birth (Sudan).

6. Case number seven (Abu Alsamha's family) together with case number eight (Almalik's family) have shown a new pattern, different from all other families. Both families have made two migration journeys to two different destination countries; also neither family made a return migration to their country of birth (Sudan).

In general, the results of the study indicate families in the Gulf States share one common pattern. All cases seemed to have returned to their country of birth (Sudan); this is in contrast to the North American families. In addition, the North American families appeared to have migrated to more than one destination country. Almost all the families in North America divide their time between Sudan, USA and Canada; they all indicated a final return to Sudan would be likely. Finally, all the families of the two groups were shown to be satisfied with their decision to migrate out of Sudan. 


\section{BIBLIOGRAPHY}

Bhugra, D. and Jones, P. (2001): Migration and Mental Illness, Advances in Psychiatric Treatment, 7, pp.216-222.

Carrión-Flores, C.E. (2007): What Makes You Go Back Home? Determinants of the Duration of Migration of Mexican Immigrants in the United States. Accessed 26 April 2012. http:// www.aeaweb.org/annual_mtg_papers/2007/0107_1015_1301.pdf .

Cobb-Clark, D. and Stillman, S. (2013): Return migration and the age profile of retirement among immigrants. IZA Journal of Migration 2(20), p.1.

Dumont, J.-C. and Spielvogel, G. (2008): Return Migration: A New Perspective. Organization for Economic Co-operation and Development, part 3. (http://www.oecd.org/migration/ mig/43999382.pdf )

Dustmann, C. and Kirchkamp, O. (2002): The optimal migration duration and activity choice after re-migration. Journal of Development Economics, 67, pp.351-372.

Efstratios, L., Anastasios, M. and Anastasios, K. (2014): Return migration: Evidence from a reception country with a short migration history. European Urban and Regional Studies 21(2), pp.161-174.

El Sheikh, M. and Al Zohairy, A. (2013): Egypt's Birth Rate Rises as Population Control Policies Vanish. New York Times.

Emirates247 News (2013): UAE, Qatar has highest expat ratio in GCC. http:// www.emirates247.com/news/emirates/uae-qatar-have-highest-expat-ratio-ingcc-2013-09-11-1.520659. Accessed May 2016.

Glennie, A. and Chappell, L. (2010): Show Me the Money (and Opportunity): Why Skilled People Leave Home - and Why They Sometimes Return. Migration Information Source, Migration Policy Institute. (http://www.migrationpolicy.org/article/show-me-money-andopportunity-why-skilled-people-leave-home-\%E2\%80\%94-and-why-they-sometimesreturn/).

Kalia, K. (2015): Return Migration: Change Directions? Migration Policy Institute, Washington DC, http://www.migrationpolicy.org/article/top-10-migration-issues-2008-issue-6\%E2\%80\%94return-migration-changing-directions. Accessed 20 January 2015.

Kuşçu, I. (2014): Ethnic Return Migration and Public Debate: The case of Kazakhstan. International Immigration 52(2), pp.178-197.

Malit Jr., F.T. and Youha, A.A. (2013): Labor Migration in the United Arab Emirates: Challenges and Responses. Migration Policy Institute, Migration Information Source. (http://www. migrationpolicy.org/article/labor-migration-united-arab-emirates-challenges-andresponses/)

OECD (2006): International Migrant Remittances and their Role in Development, PART III International Migration Outlook SOPEMI 2006, Edition OECD 2006.

OECD (2008): International Migration Outlook: SOPEMI - 2008 Edition - ISBN 9789264045651

Rietig, V. and Villegas, R.D. (2015): Stopping the Revolving Door: Reception and Reintegration Services for Central American Deportees. Migration Policy Institute, Washington DC. (http://www.migrationpolicy.org/research/stopping-revolving-doorreception-and-reintegration-services-central-american-deportees. Accessed January 2016) 
Senyurekli, A.R. and Menjivar, C. (2012): Turkish Immigrants' Hopes and Fears around Return Migration. International Migration, 50(1), pp.3-19.

Shah, N.M. (2001): International Migration: Mediterranean Basin and the Middle East. International Encyclopedia of the Social \& Behavioral Sciences, pp.7814-7819.

Shallal, M. and Abdelrahman, A. (2009): Psychological and Social Factors Affecting the Working Sudanese in the UAE, paper presented at the 10th Annual Research Conference of the UAE University, UAE, Alln, 13-16 April.

Tannenbaum, M. (2007): Back and Forth: Immigrants' Stories of Migration and Return. International Migration 45(5), pp.147-175.

Thieme, S. (2012): Coming Home? Patterns and Characteristics of Return Migration in Kyrgyzstan. International Migration 52(5), pp127-143.

Thomas-Hope, E. (1999): Return Migration to Jamaica and its Development Potential. International Migration 37(1), pp.183-207.

United Nations Statistics Division (1998): Recommendations on Statistics of International Migration, Revision 1, United Nations, New York. (http://unstats.un.org/unsd/publication/ SeriesM/seriesm_58rev1e.pdf. Accessed May 2016).

Yahirun, J.J. (2014): Take Me "Home”: Return Migration among Germany's Older Immigrants. International Migration, 52(4), pp.231-254.

Yang, D. (2004): How Remittances Help Migrant Families? Migration Information Source.

Accessed February 7, 2012. http://www.migrationinformation.org/Feature/display. cfm?ID=270.

\section{BIOGRAPHY}

Dr Musa Shallal is currently an associate professor in the United Arab Emirates University, Department of Sociology, where he has been affiliated since 1998. He holds a PhD in Sociology from lowa State University, and has worked with the Sudanese Government and the UNHCR, where he was awarded a copy of the Nobel Peace Prize. He is a founder of the University of Almughtaribeen in Sudan (2010), and a founder of its library (2013). He is heavily involved in Sudanese Community activities in the UAE. 